\title{
In vivo and in vitro protective effect of arginine against intestinal inflammatory response induced by Clostridium perfringens in broiler chickens
}

Beibei Zhang, Liping Gan, Muhammad Suhaib Shahid, Zengpeng Lv, Hao Fan, Dan Liu and Yuming Guo*i()

\begin{abstract}
Background: Necrotic enteritis is a widespread disease in poultry caused by Clostridium perfringens. We previously reported that dietary arginine supplementation protected the intestinal mucosa of broiler chickens with necrotic enteritis, but the related protective mechanisms remain unclear. The in vivo trial was designed as a $2 \times 2$ factorial arrangement to evaluated the effects of arginine supplementation on inflammatory responses, arginine transporters, arginine catabolism and JAK-STAT signalling pathway in broiler chickens challenged with C. perfringens or without C. perfringens. Furthermore, we validated the in vivo results using intestinal epithelial cells of chicken embryos.

Results: C. perfringens infection markedly increased gut gross pathological and histopathological lesion scores, promoted liver C. perfringens invasion, reduced serum arginine levels, and elevated jejunal mucosal lysozyme activities $(P<0.05)$, but these effects were significantly reversed by arginine supplementation in vivo $(P<0.05)$. The challenge significantly increased serum procalcitonin levels, jejunal mucosal iNOS activities and jejunal IL-6, TGF- $\beta 3$, cationic amino acid transporter (CAT)-1, and CAT-3 mRNA expression $(P<0.05)$, whereas arginine supplementation significantly reduced jejunal IFN- $\gamma, I L-1 \beta, I L-6, I L-10, T G F-\beta 3$, and CAT-3 mRNA expression $(P<0.05)$. Arginine supplementation significantly attenuated the $C$. perfringens challenge-induced increases in jejunal iNOS, arginase 2 , arginine decarboxylase, arginine:glycine amidinotransferase, JAK1, JAK3, STAT1, and STAT6 mRNA expression $(P<0.05)$. The in vitro experiment showed that $C$. perfringens challenge markedly increased cellular cytotoxicity and the mRNA expression of $I L-1 \beta, I L-8, I L-10, C A T-1$ and CAT-3 $(P<0.05)$, which were significantly reversed by $50 \mu \mathrm{mol} / \mathrm{L}$ and/or $400 \mu \mathrm{mol} / \mathrm{L}$ arginine pre-treatment $(P<0.05)$.
\end{abstract}

Conclusions: Arginine prevented C. perfringens challenge-induced circulated arginine deficiency, normalized intestinal arginine transport and catabolism, down-regulated JAK-STAT signalling pathway and attenuated the inflammatory response, which exerted protective effects on the intestine of broiler chickens.

Keywords: Arginine, Broiler chickens, Clostridium perfringens, Intestine inflammatory response, Metabolism

\section{Introduction}

Necrotic enteritis is a widespread avian intestinal disease which causes significant economic loss in the poultry industry [1]. In the clinical cases, this leads to depression, dehydration, diarrhoea, decreased feed intake and acute death while in subclinical cases, it generates chronic intestinal

\footnotetext{
* Correspondence: guoyum@cau.edu.cn

State Key Laboratory of Animal Nutrition, College of Animal Science and Technology, China Agricultural University, Beijing 100193, People's Republic of China
}

(c) The Author(s). 2019 Open Access This article is distributed under the terms of the Creative Commons Attribution 4.0 International License (http://creativecommons.org/licenses/by/4.0/), which permits unrestricted use, distribution, and reproduction in any medium, provided you give appropriate credit to the original author(s) and the source, provide a link to the Creative Commons license, and indicate if changes were made. The Creative Commons Public Domain Dedication waiver (http://creativecommons.org/publicdomain/zero/1.0/) applies to the data made available in this article, unless otherwise stated.

mucosal damage, poor growth performance without mortality $[2,3]$. It is certain that the overgrowth of $C$. perfringens and its extracellular toxins are the main causative agent of necrotic enteritis [2, 3]. However, several predisposing factors may be required to elicit the clinical signs and lesions of necrotic enteritis, such as coccidiosis, immunosuppressive agents, diets containing a high level of non-starch polysaccharides (wheat, rye, and barley), and a novel pore-forming toxin, NetB [3]. Due to the restrictions of antibiotic growth promoters in a growing number of 
countries and regions, the high prevalence of necrotic enteritis is prompting an active search for dietary strategies to prevent its occurrence or control its development [2].

$L$-arginine is an essential amino acid for chickens and turns out to be a conditionally essential amino acid for mammals under many stressful conditions [4-6]. The intestine is an important organ for maintaining body arginine homoeostasis [7] as arginine is actively transported and metabolized by enterocytes. Cellular arginine uptake is mainly mediated by the cationic amino acid transporter (CAT) family, also known as $\mathrm{y}^{+}$transporters, which is involved in active transport [8]. Arginine is catabolized via multiple pathways mediated by nitric oxide synthase, arginase, arginine:glycine aminotransferase (AGAT), and arginine decarboxylase (ADC) [9]. The alteration of arginine uptake and metabolism has been found to be strongly related to various enteric diseases, such as ulcerative colitis [10] and Citrobacter rodentium colitis [11]. It has been reported that infection-associated arginine deficiency contributes to intestinal immunopathology, and arginine administration can significantly attenuate intestinal inflammation and infectious complications [12]. Chau et al. [13] demonstrated that malaria-associated hyperargininaemia could impair intestinal barrier functions, rendering the host vulnerable to Salmonella coinfection. Increasing arginine bioavailability through oral supplementation can ameliorate intestinal inflammation and pathological lesions. In a Citrobacter rodentium-induced colitis model, serum arginine levels of the infected mice were significantly lower than those of the uninfected mice, and arginine supplementation was clinically beneficial [11]. Thus, dietary arginine administration may be a necessary strategy for maintaining arginine homeostasis under many physiological and pathological conditions to maintain good health and bodily functions [14].

The Janus kinase (JAK)-signal transducer and activator of transcription (STAT) cascade is a critical signaling pathway in inflammatory responses [15]. It mediates the transcription of inflammatory cytokines, including $I L-6, I L-1 \beta$ and TNF- $\alpha$, and inducible enzymes such as cyclooxygenase- 2 and inducible nitric oxide synthase (iNOS) in mammals [16, 17]. Truong et al. [18] demonstrated that mRNA expression of $J A K 1, J A K 2, J A K 3$, and STAT1 in the spleen of broilers suffering from necrotic enteritis were dramatically elevated compared with that of healthy birds. However, little is known about the role of the JAKSTAT signalling pathway in the protective effect of arginine supplementation against necrotic enteritis in broiler chickens.

We previously demonstrated that dietary arginine supplementation protected the intestinal mucosa of broiler chickens with necrotic enteritis by promoting innate immune responses, improving intestinal absorption and barrier function, and inhibiting C. perfringens colonization [19]. However, the effects of dietary arginine supplementation on intestinal arginine transport, metabolism and the related protective mechanism in broilers with necrotic enteritis remain uncertain. Thus, the present study was designed to determine the effects of arginine supplementation on inflammatory responses induced by $C$. perfringens in vivo and in vitro, and explore the associated, potentially protective mechanisms.

\section{Materials and methods In vivo experiments Animals and experimental treatments}

In a $2 \times 2$ factorial arrangement, 140 one-day-old male Arbor Acres broiler chickens were randomly allocated to four groups, with 35 birds per group. The treatments were as follows: CON group, received a basal diet; ARG group, fed a basal diet supplemented with $3 \mathrm{~g} / \mathrm{kg}$ arginine; $\mathrm{CON}+\mathrm{CP}$ group, received a basal diet and underwent $C$. perfringens challenge; and $\mathrm{ARG}+\mathrm{CP}$ group, given a basal diet supplemented with $3 \mathrm{~g} / \mathrm{kg}$ arginine and underwent $C$. perfringens challenge. The basal diet was formulated according to the recommendations by the National Research Council (NRC 1994), and alanine was used to keep crude protein level constant for different diets (Table 1). High-performance liquid chromatography (HPLC) was used to determine the dietary amino acid levels. Each group of birds was kept in a separate rearing isolator $(1.6 \mathrm{~m} \times 0.7 \mathrm{~m} \times 0.7 \mathrm{~m})$. Each isolator contains a wire mesh floor and was equipped with two nipple drinkers and one feeder. Air was pumped into the isolator and the room housed with the isolators was air-conditioned. The birds were maintained on a $23 \mathrm{~h} / \mathrm{d}$-lighting programme and routinely immunized. The experiment lasted for $21 \mathrm{~d}$.

\section{C. perfringens challenge}

A chicken C. perfringens type A strain (CVCC2030, China Veterinary Culture Collection Center, Beijing, China) was used to establish a necrotic enteritis model based on the method of a previous study [20]. Briefly, the $C$. perfringens strain was cultured anaerobically in a broth culture medium containing beef pellets overnight at $37{ }^{\circ} \mathrm{C}$, and the viable bacteria were counted on tryptose-sulfite-cycloserine agar (CM138, Land Bridge Technology Ltd., Beijing, China) plates with $D$-cycloserine supplement (P-15B, Land Bridge Technology Ltd., Beijing, China). From d 14 to d 20, $1 \mathrm{~mL}$ $\left.(2 \sim 3) \times 10^{8} \mathrm{CFU} / \mathrm{mL}\right)$ of fresh $C$. perfringens culture was orally administered to all birds in the challenged groups (group $\mathrm{CON}+\mathrm{CP}$ and $\mathrm{ARG}+\mathrm{CP}$ ) per day, while birds in 
Table 1 Diet composition and nutrient levels

\begin{tabular}{|c|c|c|}
\hline Items & Control diet & L-arginine-supplemented diet \\
\hline \multicolumn{3}{|c|}{ Ingredient, g/kg (unless otherwise indicated) } \\
\hline Corn & 582.8 & 582.8 \\
\hline Soybean meal, $44 \%$ CP & 291.1 & 291.1 \\
\hline Corn gluten meal & 50.0 & 50.0 \\
\hline Soybean oil & 25.0 & 25.0 \\
\hline Dicalcium phosphate & 19.2 & 19.2 \\
\hline Limestone & 8.9 & 8.9 \\
\hline Sodium chloride & 3.0 & 3.0 \\
\hline Choline chloride, $50 \%$ & 2.5 & 2.5 \\
\hline Mineral premix $x^{a}$ & 2.0 & 2.0 \\
\hline D,L-Methionine, $98 \%$ & 2.6 & 2.6 \\
\hline L-Lys-HCl, 98\% & 2.4 & 2.4 \\
\hline Vitamin premix ${ }^{\mathrm{b}}$ & 0.3 & 0.3 \\
\hline Ethoxyquin, 33\% & 0.2 & 0.2 \\
\hline L-Arg & 0.0 & 4.0 \\
\hline L-Ala & 10.0 & 6.0 \\
\hline \multicolumn{3}{|c|}{ Nutrient level', g/kg (unless otherwise indicated) } \\
\hline $\mathrm{ME}, \mathrm{Mcal} / \mathrm{kg}$ & 2.98 & 2.98 \\
\hline $\mathrm{CP}$ & 219.4 & 219.4 \\
\hline $\mathrm{Ca}$ & 10.0 & 10.0 \\
\hline Non-phytate phosphorus & 4.5 & 4.5 \\
\hline Lys, measured value & 13.6 & 13.9 \\
\hline Met & 5.9 & 5.9 \\
\hline Thr, measured value & 8.6 & 8.8 \\
\hline Arg, measured value & 14.2 & 17.2 \\
\hline
\end{tabular}

${ }^{\text {aS }}$ upplied per kilogram of complete feed: $\mathrm{Mn}, 100 \mathrm{mg} ; \mathrm{Fe}, 80 \mathrm{mg} ; \mathrm{Zn}, 75 \mathrm{mg} ; \mathrm{Cu}, 8 \mathrm{mg} ; \mathrm{l}, 0.35 \mathrm{mg}$; and Se, $0.15 \mathrm{mg}$

${ }^{b}$ Supplied per kilogram of complete feed: vitamin $A, 12,500 \mathrm{IU}$; vitamin $\mathrm{D}_{3}$, $2500 \mathrm{IU}$; vitamin $\mathrm{E}, 30 \mathrm{IU}$; vitamin $\mathrm{K}_{3}, 2.65 \mathrm{mg}$; vitamin $\mathrm{B}_{1}, 2 \mathrm{mg}$; vitamin $\mathrm{B}_{2}, 6 \mathrm{mg}$;

vitamin $B_{5}, 12 \mathrm{mg}$; vitamin $B_{12}, 0.025 \mathrm{mg}$; niacin, $50 \mathrm{mg}$; folic acid, $1.25 \mathrm{mg}$ and biotin, $0.0325 \mathrm{mg}$

'Calculated composition, unless otherwise indicated

the non-challenged groups (group CON and ARG) received equal volumes of sterile broth culture medium.

\section{Sample collection}

On d 21, eight birds from each group were randomly selected, and blood samples were individually collected from the wing vein and then were centrifuged at 3,000 r/min for $10 \mathrm{~min}$ at $4{ }^{\circ} \mathrm{C}$ to obtain serum for determining arginine and procalcitonin concentrations. Then, the chickens were killed by intravenous injection of pentobarbital sodium ( $30 \mathrm{mg} / \mathrm{kg}$ body weight) and jugular exsanguination. The midregion of the jejunum $(\sim 1 \mathrm{~cm})$ was sampled, flushed gently with saline to remove digesta and immediately frozen in liquid nitrogen, and stored at $-80^{\circ} \mathrm{C}$ for subsequent RNA extraction. Mucosa from the second half of the jejunum (from the midpoint of jejunum to Meckel's diverticulum) was scrapped, immediately frozen in liquid nitrogen and stored at $-20^{\circ} \mathrm{C}$ for subsequent determination of lysozyme and iNOS activities.

\section{Intestinal lesion score and histopathological examination}

The gross macroscopic lesions were scored according to the method of Dahiya et al. [21] with some modifications. The small intestine from each bird was firstly observed from the serosal side, then opened longitudinally and last observed from the mucosal side. The lesion scores system was as follows: $0=$ normal appearance, no lesion; $0.5=$ severely congested serosa and mesentery engorged with blood; $1=$ thin-walled and friable intestine with small red petechiae $(>5)$; 2 focal necrosis and small amounts of gas production; 3 = patches of necrosis ( 1 to $2 \mathrm{~cm}$ long) and gasfilled intestine; and 4 =diffused necrosis and large amounts of gas. For histopathological examination, jejuna of experimental birds were preserved in $4 \%$ paraformaldehyde prior to being dehydrated, embedded in 
paraffin, sectioned, and stained with hematoxylin and eosin. Histopathological scores were determined according to the method of Jerzsele et al. [22] with some modifications and the scoring criteria were as follows: (i) epithelial cell defects, (ii) lympho-histiocytic infiltration, (iii) villus fusion, (iv) capillary dilation, (v) capillary hemorrhages, (vi) erosion of the epithelial layer. Each attribute was scored using a scale from 0 to $3(0$, none; 1 , mild; 2 , moderate and 3 , severe), and then these were summarized and total scores were attached to each sample. Both gross macroscopic lesions and microscopic histopathological evaluation were scored in a blinded fashion.

\section{Liver C. perfringens enumerations}

The livers from 8 birds per treatment were collected for C. perfringens enumerations by plate count. Approximately $0.3 \mathrm{~g}$ of each liver sample was weighted, aseptically collected into $5-\mathrm{mL}$ sterile centrifuge tubes, diluted to 1 : 10 with sterile normal saline and then homogenized using a high-throughput tissue homogenizer (Scientz, Ningbo, China). The liver homogenate was serially diluted with sterile normal saline from $10^{-1}$ to $10^{-2}$, and then $100 \mu \mathrm{L}$ of each sample diluent was plated on tryptose-sulfitecycloseine agar with $D$-cycloserine supplement for $C$. perfringens enumeration in duplicate. The $C$. perfringens was counted after anaerobic incubation for $24 \mathrm{~h}$ at $37^{\circ} \mathrm{C}$. The result was expressed as colony forming units (CFUs) per gram of liver.

\section{Serum procalcitonin determination}

Serum procalcitonin levels were measured using a chicken procalcitonin ELISA kit (Beijing Jinhai Keyu Biotech Development Co., Ltd., Beijing, China) according to the manufacturer's guidelines.

\section{Serum arginine concentration assay}

Serum samples $(40 \mu \mathrm{L})$ were transferred to $1.5-\mathrm{mL}$ centrifuge tubes, with $40 \mu \mathrm{L}$ of $\mathrm{HClO}_{4}(1.5 \mathrm{~mol} / \mathrm{L})$ added to remove proteins and $20 \mu \mathrm{L}$ of $\mathrm{K}_{2} \mathrm{CO}_{3}$ solution added to neutralize the $\mathrm{pH}$. The mixture was diluted with $900 \mu \mathrm{L}$ of HPLC-grade water and centrifuged at $10,000 \times g$ for $10 \mathrm{~min}$ to precipitate the pellet. The resultant supernatant was used to analyze the arginine concentration following the method of Wu and Meininger [23].

\section{Assay for lysozyme and iNOS activities in the jejunal mucosa}

The jejunal mucosa $(0.3 \mathrm{~g})$ was added to $2.7 \mathrm{~mL}$ of sterile saline, homogenized, and centrifuged at 3,000 r/min for $10 \mathrm{~min}$ at $4{ }^{\circ} \mathrm{C}$. The supernatant was assayed for lysozyme and iNOS activities using the Lysozyme Assay Kit and the Inducible Nitric Oxide Synthase Assay Kit, respectively, from Nanjing Jiancheng Bioengineering
Institute (Nanjing, China) following the manufacturer's protocols. The results are expressed as units/mg of mucosal protein. The concentration of protein was determined using the BCA Assay Kit (CWBio, Inc., Beijing, China).

\section{Jejunal gene expression assay}

RNA extraction and real-time PCR were performed as described in a previous study from our lab [24]. Briefly, total RNA was isolated from the jejunal tissues using Trizol reagent (Invitrogen Life Technologies, Carlsbad, California). cDNA was generated using the PrimeScript RT reagent kit with cDNA eraser (Takara, Dalian, China). Quantitative PCR assays were carried out using the SYBR ${ }^{\circ}$ Premix Ex Taq $^{\text {Tix }}$ kit (Takara, Dalian, China). Target gene expression was quantified using the $2^{-\triangle \Delta C T}$ method [25] and normalized to the expression of GAPDH. The PCR primer sequences are shown in Table 2.

\section{In vitro experiments \\ Cell culture and treatment}

The isolation procedure of primary intestinal epithelial cells (IEC) from chicken embryos were performed as described previously [26]. Chicken IEC were grown in Dulbecco's Modified Eagles Medium/Nutrient Mixture F-12 (DMEM/F12) medium (Macgene technology, Beijing, China) containing $2.5 \%$ fetal bovine serum (Gibco, Carlsbad, CA), 1\% penicillin-streptomycin (Macgene technology, Beijing, China), $100 \mu \mathrm{g} / \mathrm{mL}$ heparin sodium salt, $5 \mu \mathrm{g} / \mathrm{mL}$ insulin and $20 \mathrm{ng} / \mathrm{mL}$ epidermal growth factor (BD Biosciences, San Jose, CA). All other chemicals, unless indicated, were purchased from Sigma-Aldrich (St. Louis, MO). Isolated cells $\left(5 \times 10^{6}\right)$ were seeded in 6-well culture plates (Corning Life Science, Tewksbury, MA) with a total volume of $2 \mathrm{~mL}$ of DMEM/F12. After $48 \mathrm{~h}$ of incubation, the cells were starved for $8 \mathrm{~h}$ in custom-made arginine-free DMEM/F12 (Merck Millipore Beijing Skywing, Beijing, China) containing 1\% penicillinstreptomycin. Then they were washed with pre-washed phosphate-buffered saline (PBS) twice and allocated into 4 groups: group 1, cultured in arginine-free media without C. perfringens challenge; group 2, cultured in arginine-free media prior to C. perfringens challenge; group 3, cultured in $50 \mu \mathrm{mol} / \mathrm{L}$ arginine prior to $C$. perfringens challenge; group 4, cultured in $400 \mu \mathrm{mol} / \mathrm{L}$ arginine prior to $C$. perfringens challenge. After a 6-h period of culture in custom-made DMEM/F12 containing $0 \mu \mathrm{mol} / \mathrm{L}$, $50 \mu \mathrm{mol} / \mathrm{L}$ or $400 \mu \mathrm{mol} / \mathrm{L} L$-arginine, the cells were washed with PBS twice and then cultured for $4 \mathrm{~h}$ in $2 \mathrm{~mL}$ arginine-free DMEM/F12 containing C. perfringens at multiplicity of infection (MOI, the ratio of bacteria to eukaryotic cells) of 1:1 or equal volume PBS. Following $4 \mathrm{~h}$ of incubation, media were collected, centrifuged at 
Table 2 Primers used for real-time PCR analysis ${ }^{\mathrm{a}}$

\begin{tabular}{|c|c|c|c|c|}
\hline Gene name & Primer sequence ( $5^{\prime}$ to $\left.3^{\prime}\right)$ & Product size, bp & Efficiency, \% & Accession number \\
\hline \multirow[t]{2}{*}{ CAT-1 } & F: ATGTAGGTTGGGATGGAGCC & 280 & 113.556 & XM_015277949.1 \\
\hline & R: AACGAGTAAGCCAGGAGGGT & & & \\
\hline \multirow[t]{2}{*}{ CAT-2 } & F: CAAGTCTTCTCGGCTCTAT & 105 & 105.602 & XM_015285435.1 \\
\hline & R: GTGCCTGCCTCTTACTCA & & & \\
\hline \multirow[t]{2}{*}{ CAT-3 } & F: CAAGACTGGCTCTGCCTACC & 236 & 106.623 & XM_015278426.1 \\
\hline & R: GGATCAACGCAAAGAAGTCC & & & \\
\hline \multirow[t]{2}{*}{ iNOS } & F: TGGGTGGAAGCCGAAATA & 241 & 103.087 & NM_204961.1 \\
\hline & R: GTACCAGCCGTTGAAAGGAC & & & \\
\hline \multirow[t]{2}{*}{$A R G 2$} & F: GCCAACTGTACGACTTTGGAG & 150 & 90.430 & NM_001199704.1 \\
\hline & R: AGCTGTGTCCAGCAGCTACC & & & \\
\hline \multirow[t]{2}{*}{$A D C$} & F: CCCAGTTTGAGGAGATTGCT & 122 & 108.230 & XM_004947849.2 \\
\hline & R: AAAGGTGAAGGCTGAGGTGA & & & \\
\hline \multirow[t]{2}{*}{ AGAT } & F: TCGTCAAGAGGCCTGATCCA & 140 & 111.489 & XM_015291975.1 \\
\hline & R: CCAAGCCATAGGCGCTTCAA & & & \\
\hline \multirow[t]{2}{*}{$I L-1 \beta$} & F: ACTGGGCATCAAGGGCTA & 131 & 104.419 & XM_015297469.1 \\
\hline & R: GGTAGAAGATGAAGCGGGTC & & & \\
\hline \multirow[t]{2}{*}{ IL-6 } & F: CGCCCAGAAATCCCTCCTC & 152 & 101.974 & XM_015281283.1 \\
\hline & R: AGGCACTGAAACTCCTGGTC & & & \\
\hline \multirow[t]{2}{*}{ IL-8 } & F: ATGAACGGCAAGCTTGGAGCTG & 233 & 119.885 & NM_205498.1 \\
\hline & R: TCCAAGCACACCTCTCTTCCATCC & & & \\
\hline \multirow[t]{2}{*}{ IFN- $\gamma$} & F: AGCTGACGGTGGACCTATTATT & 259 & 108.556 & NM_205149.1 \\
\hline & R: GGCTTTGCGCTGGATTC & & & \\
\hline \multirow[t]{2}{*}{$\operatorname{lL}-10$} & F: CGCTGTCACCGCTTCTTCA & 88 & 98.435 & NM_001004414.2 \\
\hline & R: TCCCGTTCTCATCCATCTTCTC & & & \\
\hline \multirow[t]{2}{*}{ TGF- $\beta 3$} & F: CATCGAGCTCTTCCAGATCC & 112 & 102.986 & NM_205454.1 \\
\hline & R: GACATCGAAGGACAGCCACT & & & \\
\hline \multirow[t]{2}{*}{ JAK1 } & F: TGCACCGTGACTTAGCAGCAAG & 168 & 114.087 & XM_015290965.1 \\
\hline & R: TCTGAATCAAGCATTCTGGAGCATACC & & & \\
\hline \multirow[t]{2}{*}{ JAK2 } & F: TCGCTATGGCATTATTCG & 197 & 110.029 & XM_015280061.1 \\
\hline & R: GTGGGGTTTGGTCCTTT & & & \\
\hline \multirow[t]{2}{*}{ JAK3 } & F: GCATCCGCCGCCGTGTTG & 108 & 96.164 & NM_204996.3 \\
\hline & R: AGCACCGCAGCCTCTCCAG & & & \\
\hline \multirow[t]{2}{*}{ STAT1 } & F: TAAAGAGGGAGCAATCAC & 112 & 109.954 & XM_015289392.1 \\
\hline & R: ATCAGGGAAAGTAACAGC & & & \\
\hline \multirow[t]{2}{*}{ STAT6 } & F: GCAACCTCTACCCCAACA & 127 & 101.256 & XM_015274736.1 \\
\hline & R: TCCCTTTCGCTTTCCACT & & & \\
\hline \multirow[t]{2}{*}{ GAPDH } & F: TGCTGCCCAGAACATCATCC & 142 & 98.200 & NM_204305.1 \\
\hline & R: ACGGCAGGTCAGGTCAACAA & & & \\
\hline
\end{tabular}

${ }^{a}$ Abbreviations: CAT Cationic amino acid transporter, iNOS inducible nitric oxide synthase, ARG2 Arginase 2, ADC Arginine decarboxylase, AGAT Arginine: glycine amidinotransferase, IFN- $\gamma$ Interferon- $\gamma$, TGF- $\beta 3$ Transforming growth factor- $\beta 3$, JAK Janus kinase, STAT Signal transducer and activator of transcription, GAPDH Glyceraldehyde-3-phosphate dehydrogenase, $F$ Forward, $R$ Reverse

$4,000 \times g$ for $10 \mathrm{~min}$ to obtain supernatant for analyzing lactic dehydrogenase (LDH) release, and cells were collected for RNA extraction. Each treatment included 6 wells.

\section{Cytotoxicity measurement}

$\mathrm{LDH}$, a cytoplasmic enzyme, is quickly released into the extracellular environment when the plasma membrane of a cell is injured [27]. In the in vitro experiment, cytotoxicity 
was assessed by the levels of LDH in the cell supernatant using the LDH cytotoxicity assay kit (Beyotime Biotechnology, Beijing, China).

\section{Cellular RNA isolation and gene expression}

Total RNA of chicken IEC was extracted and gene expression was measured by RT-PCR as described above.

\section{Statistical analysis}

Data were analyzed using a two-factor ANOVA of a general linear model for the in vivo experiment and one-way ANOVA for the in vitro experiment using SPSS version 18.0. A univariate ANOVA and Duncan's multiple comparisons were carried out for significant interactive effects in vivo. Differences were considered statistically significant at $P \leq 0.05$. Data are presented as means \pm SEMs.

\section{Results}

Intestinal gross pathological and histopathological examination, and liver C. perfringens invasion in vivo Most of the birds with only $C$. perfringens challenge showed depression, diarrhea, and inappetence. Furthermore, one bird died in $\mathrm{CON}+\mathrm{CP}$ group, as well as $\mathrm{ARG}+\mathrm{CP}$ group, in which necrotic enteritis was confirmed pathologically. There was no mortality in the unchallenged groups. A high percentage of animals with only C. perfringens challenge exhibited marked intestinal lesion, include hyperemia, bleeding spots, thinner intestinal walls, and gas generation. According to Fig. 1a, the chickens with only $C$. perfringens challenge had the highest intestinal lesion score $(P<0.05)$, but dietary arginine supplementation significantly decreased intestinal lesion score in $C$. perfringens challenged birds $(P<0.05)$. The results of the histopathological evaluation were mainly in agreement with that of the gross lesion examination (Fig. 1b). As shown in Fig. 1c, the jejuna of

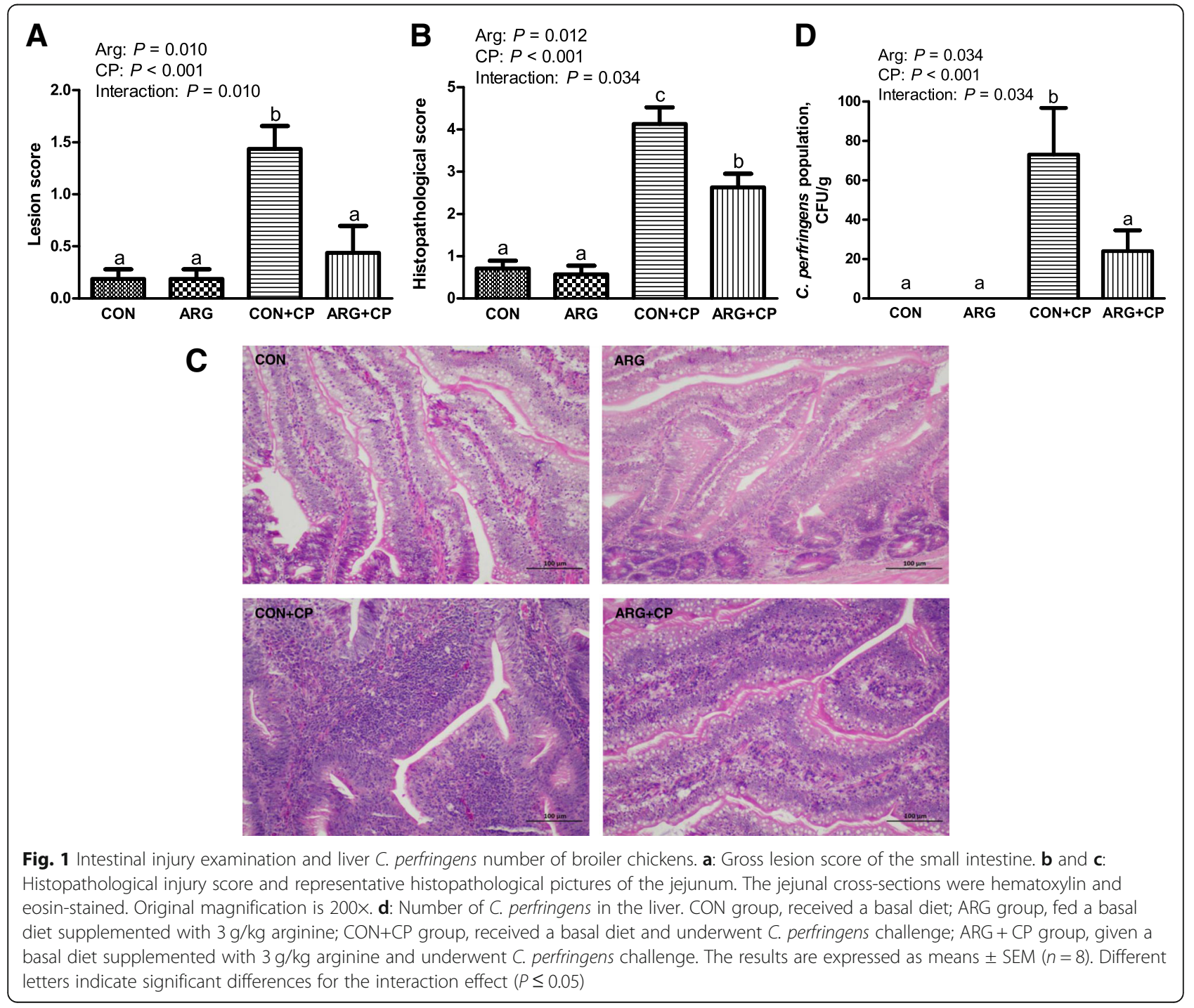


birds in the CON group and the ARG group were almost normal, except for the presence of a few of lymphocytes. However, distinct epithelial cell defects, villus fusion, capillary hemorrhages, lymphocytes infiltration into the lamina propria and crypt abscesses were observed in most of the birds with only $C$. perfringens challenge. The degree of histopathological injury in ARG $+\mathrm{CP}$ group was significantly less than that in $\mathrm{CON}+\mathrm{CP}$ group $(P<0.05)$. Figure $1 \mathrm{~d}$ shows that there was a significant interaction effect between $C$. perfringens challenge and arginine addition on the number of $C$. perfringens in the liver $(P<0.05)$. No $C$. perfringens was detected in the livers of unchallenged birds. Challenged birds fed basal diets had a significantly higher number of $C$. perfringens in the liver than that in the unchallenged birds $(P<0.05)$. Challenged birds fed diets supplemented with arginine significantly reduced the liver $C$. perfringens number compared with the challenged birds fed basal diets $(P<$ 0.05).

\section{Serum procalcitonin and arginine levels in vivo}

Serum procalcitonin and arginine levels are shown in Fig. 2. C. perfringens challenge significantly increased the serum procalcitonin levels of birds $(P<0.05)$. A significant interaction was found between arginine supplementation and $C$. perfringens challenge on serum procalcitonin levels $(P<0.05)$. Compared with the $\mathrm{CON}$ group, the $\mathrm{CON}+\mathrm{CP}$ group significantly increased the serum procalcitonin level $(P<0.05)$. However, arginine supplementation did not affect the serum procalcitonin level $(P>0.05)$. There was a significant interaction between arginine supplementation and $C$. perfringens challenge on the serum arginine levels $(P=0.05)$. The serum arginine level in the $\mathrm{CP}$ group was significantly lower than that in the CON group $(P<0.05)$, whereas chickens receiving the arginine supplementeddiet (ARG and ARG + CP groups) had significantly increased serum arginine levels $(P<0.05)$.

\section{Lysozyme and iNOS activities of jejunal mucosa in vivo}

Significant increases in lysozyme and iNOS activities in the jejunal mucosa were observed after $C$. perfringens challenge $(P<0.05 ;$ Fig. 3$)$. Compared with the effect of the basal diet, arginine supplementation significantly decreased lysozyme activity $(P<0.05)$ in the jejunal mucosa.

\section{Gene expression of jejunal inflammatory cytokines in vivo} As shown in Fig. 4, C. perfringens challenge significantly enhanced the mRNA expression of $I L-6$ and TGF- $\beta 3$ $(P<0.05)$ in the jejunum. Arginine supplementation significantly reduced the mRNA expression of $I L-1 \beta, I L-6$, $I F N-\gamma, I L-10$, and TGF- $\beta 3(P<0.05)$ in the jejunum. Furthermore, the interaction between the effects of arginine supplementation and $C$. perfringens challenge dramatically influenced jejunal $I L-6$ mRNA expression $(P<0.05)$. IL-6 mRNA expression in the $\mathrm{CP}$ group was the highest among the four groups, and there were no significant differences among the other three groups.

\section{Gene expression of jejunal cationic amino acid transporters in vivo}

As shown in Table 3, the challenged groups had higher CAT-1 mRNA expression in the jejunum than did the unchallenged groups $(P<0.05)$. Arginine supplementation significantly suppressed jejunal $C A T-2$ and $C A T-3$ mRNA expression $(P<0.05)$. A significant interaction was found between the effects of arginine supplementation and $C$. perfringens challenge on jejunal CAT-3 mRNA expression $(P<0.05)$. The birds with only $C$. perfringens challenge had the highest jejunal CAT-3 mRNA expression, and arginine supplementation significantly reduced jejunal $C A T-3$ mRNA expression in the challenged birds $(P<0.05)$.
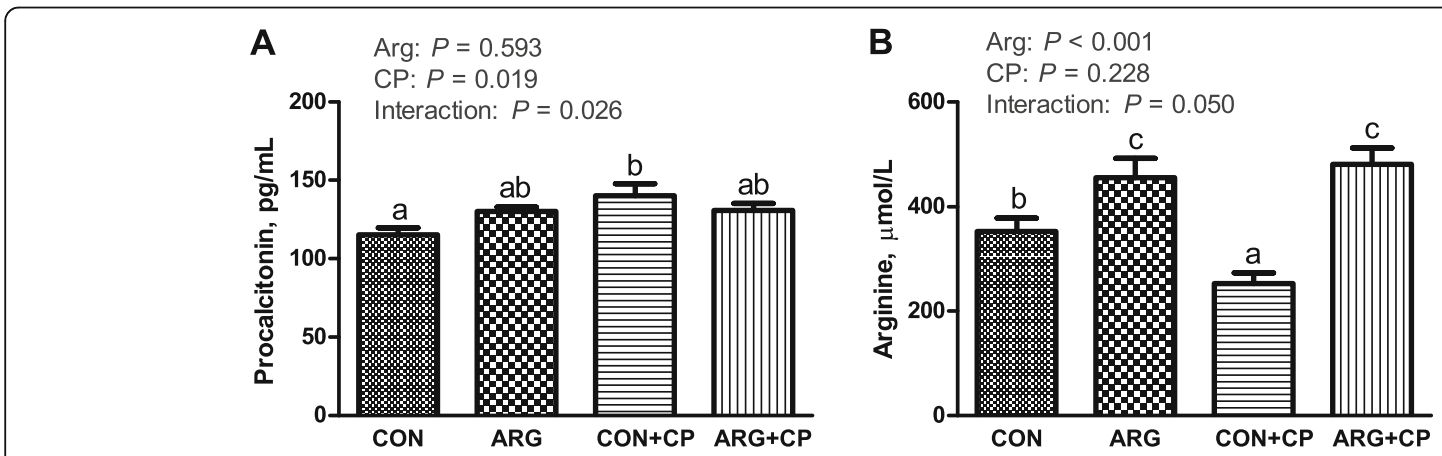

Fig. 2 Serum procalcitonin (a) and arginine (b) concentrations of broiler chickens. CON group, received a basal diet; ARG group, fed a basal diet supplemented with $3 \mathrm{~g} / \mathrm{kg}$ arginine; CON+CP group, received a basal diet and underwent $\mathrm{C}$. perfringens challenge; ARG + CP group, given a basal diet supplemented with $3 \mathrm{~g} / \mathrm{kg}$ arginine and underwent $C$. perfringens challenge. The results are expressed as means $\pm \operatorname{SEM}(n=8)$. Different letters indicate significant differences for the interaction effect $(P \leq 0.05)$ 

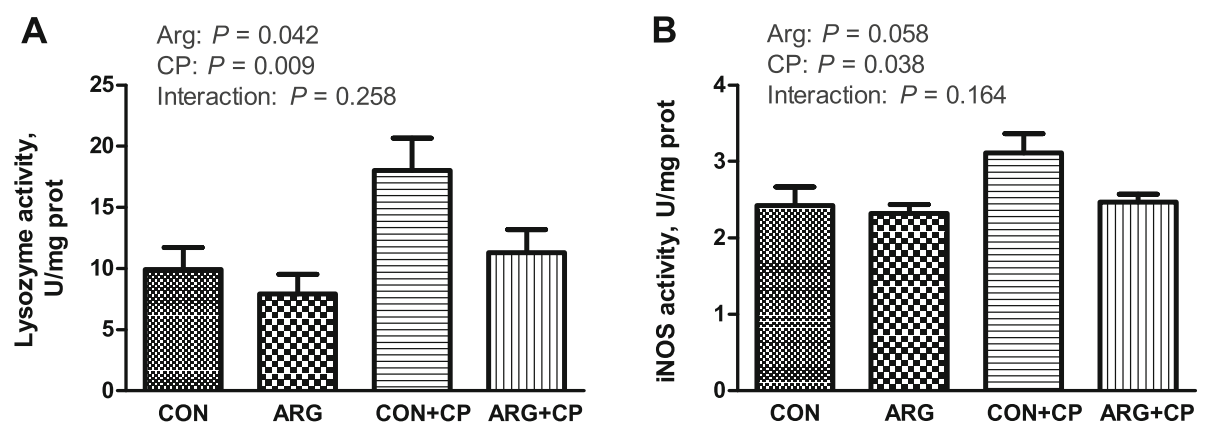

Fig. 3 Jejunal mucosal lysozyme (a) and iNOS (b) activities of broiler chickens. CON group, received a basal diet; ARG group, fed a basal diet supplemented with $3 \mathrm{~g} / \mathrm{kg}$ arginine; $\mathrm{CON}+\mathrm{CP}$ group, received a basal diet and underwent $\mathrm{C}$. perfringens challenge; ARG + CP group, given a basal diet supplemented with $3 \mathrm{~g} / \mathrm{kg}$ arginine and underwent $C$. perfringens challenge. iNOS, inducible nitric oxide synthase. The results are expressed as means $\pm \operatorname{SEM}(n=8)$

\section{Gene expression of the jejunal arginine catabolic} enzymes in vivo

As shown in Table 3, C. perfringens infection significantly increased the mRNA expression of $i N O S$ and arginase 2 (ARG2) $(P<0.05)$ in the jejunum of birds. Arginine supplementation significantly decreased the mRNA expression of $i N O S, A R G 2, A D C$, and $A G A T$ $(P<0.05)$. There were interactions between the effects of arginine supplementation and $C$. perfringens challenge on jejunal iNOS and $A D C$ mRNA expression $(P<0.05)$. Compared with the CON and the ARG groups, the CP group had higher mRNA expression levels of $i N O S$ and
$A D C$ in the jejunum $(P<0.05)$; however, the $\mathrm{ARG}+\mathrm{CP}$ group significantly downregulated the mRNA expression for both of these enzymes compared with that in the CP group $(P<0.05)$.

\section{Gene expression of jejunal JAK-STAT signaling pathway components in vivo}

Figure 5 demonstrates that $C$. perfringens challenge induced a significant increase in jejunal $J A K 3$ mRNA expression $(P<0.05)$. Arginine supplementation led to a reduction in jejunal JAK1, STAT1, and STAT6 mRNA expression $(P<$ 0.05). The effects of arginine supplementation and $C$.

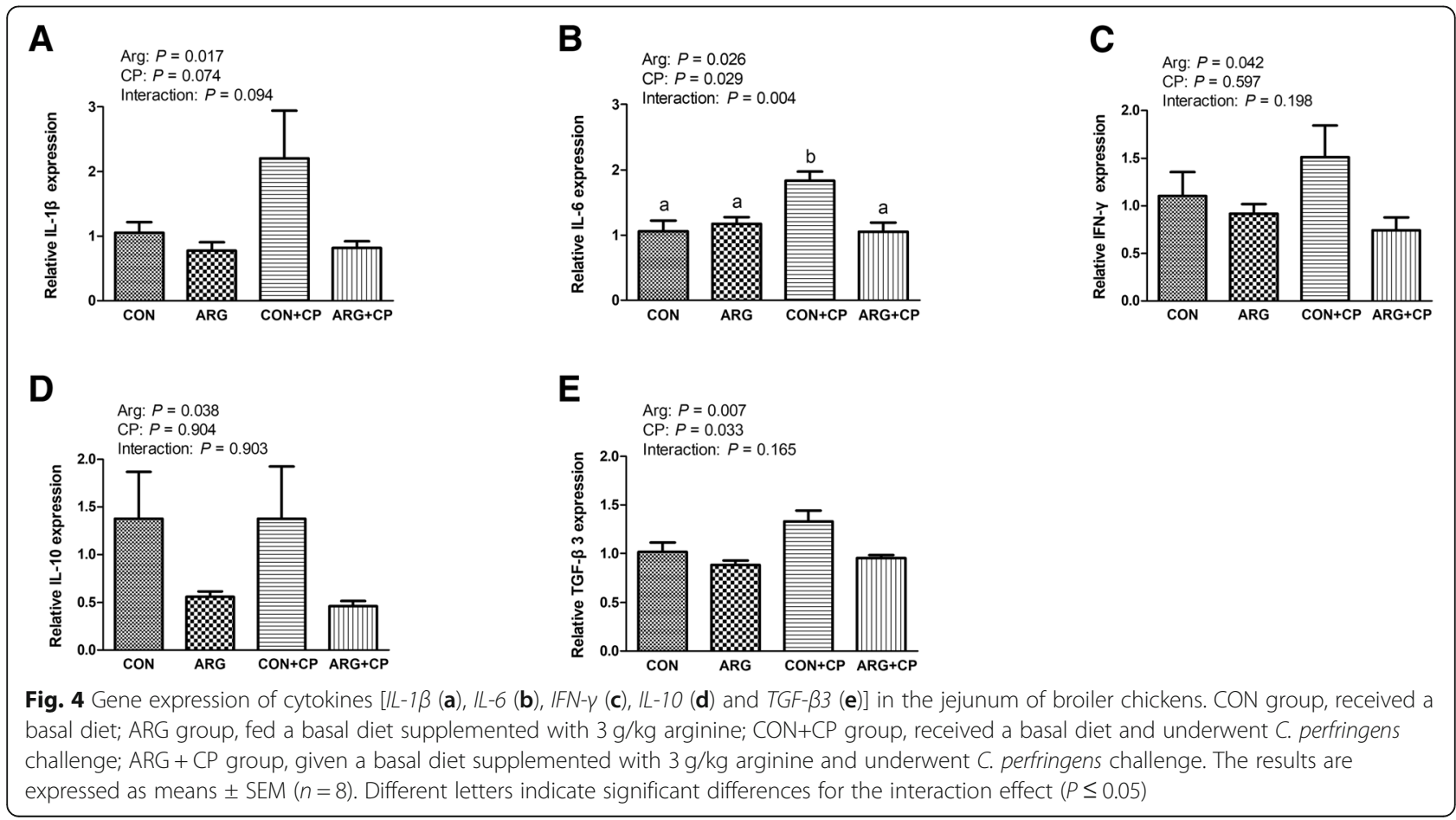


Table 3 Gene expression of CATs and arginine catabolic enzymes in the jejunum of broiler chickens

\begin{tabular}{llllllll}
\hline Items $^{c}$ & CAT $^{\mathrm{d}}-1$ & CAT-2 & CAT-3 & iNOS $^{\mathrm{e}}$ & ARG2 $^{\mathrm{f}}$ & ADC $^{\mathrm{g}}$ & AGAT $^{\mathrm{h}}$ \\
\hline CON & 1.00 & 1.03 & $1.01^{\mathrm{a}}$ & $1.02^{\mathrm{a}}$ & 1.02 & $1.03^{\mathrm{a}}$ & 1.01 \\
ARG & 1.05 & 0.64 & $0.98^{\mathrm{a}}$ & $1.02^{\mathrm{a}}$ & 0.79 & $0.93^{\mathrm{a}}$ & 0.59 \\
CON+CP & 1.38 & 1.01 & $1.28^{\mathrm{b}}$ & $1.73^{\mathrm{b}}$ & 1.31 & $1.35^{\mathrm{b}}$ & 1.03 \\
ARG + CP & 1.09 & 0.61 & $0.89^{\mathrm{a}}$ & $0.93^{\mathrm{a}}$ & 0.99 & $0.79^{\mathrm{a}}$ & 0.92 \\
SEM & 0.049 & 0.063 & 0.047 & 0.087 & 0.067 & 0.066 & 0.056
\end{tabular}

Main effect

\begin{tabular}{|c|c|c|c|c|c|c|c|}
\hline \multirow[t]{2}{*}{ Arg } & $-\quad 1.21$ & 1.02 & 1.15 & 1.38 & 1.16 & 1.19 & 1.02 \\
\hline & +1.07 & 0.62 & 0.93 & 0.98 & 0.88 & 0.87 & 0.76 \\
\hline \multirow[t]{2}{*}{$C P$} & $-\quad 1.03$ & 0.84 & 0.99 & 1.02 & 0.92 & 0.98 & 0.80 \\
\hline & +1.23 & 0.81 & 1.09 & 1.33 & 1.18 & 1.09 & \\
\hline
\end{tabular}

$P$-value

$\begin{array}{llllllll}\text { Arg } & 0.169 & 0.001 & 0.008 & 0.003 & 0.028 & 0.006 & 0.008 \\ \text { CP } & 0.022 & 0.789 & 0.209 & 0.018 & 0.048 & 0.432 & 0.059 \\ \text { Interaction } & 0.060 & 0.994 & 0.023 & 0.003 & 0.661 & 0.041 & 0.089\end{array}$

${ }^{\mathrm{a}, \mathrm{b}}$ Different letters indicate significant differences for the interaction effect $(P \leq 0.05)$

${ }^{\mathrm{C}} \mathrm{CON}$ group, received a basal diet; ARG group, fed a basal diet supplemented with $3 \mathrm{~g} / \mathrm{kg}$ arginine; $\mathrm{CON}+\mathrm{CP}$ group, received a basal diet and underwent $C$. perfringens challenge; ARG + CP group, given a basal diet supplemented with $3 \mathrm{~g} / \mathrm{kg}$ arginine and underwent $C$. perfringens challenge

${ }^{\mathrm{d}}$ CAT Cationic amino acid transporter

eiNOS Inducible nitric oxide synthase

${ }^{\mathrm{f}}$ ARG2 Arginase2

${ }^{\mathrm{g}} A D C$ Arginine decarboxylase

${ }^{\mathrm{h}}$ AGAT Arginine:glycine amidinotransferase perfringens challenge had a significant interaction on the mRNA expression of JAK1, JAK3, STAT1, and STAT6 in the jejunum of broiler chickens $(P<0.05)$. Compared with the control group, birds treated with only $C$. perfringens challenge had markedly increased the gene expression of JAK1, JAK3, STAT1, and STAT6 in the jejunum $(P<0.05)$, while arginine supplementation significantly reversed these elevated gene expressions in the jejunum of birds challenged with $C$. perfringens $(P<0.05)$.

\section{Cytotoxicity, inflammation responses and the mRNA expression of CATs in vitro}

Figure 6 shows that $C$. perfringens challenge caused a significant increase in the cytotoxicity when compared with the unchallenged chicken IEC $(P<0.001)$. However, pretreatment with arginine $(50 \mu \mathrm{mol} / \mathrm{L}$ and $400 \mu \mathrm{mol} / \mathrm{L})$ prior C. perfringens challenge significantly decreased the cytotoxicity $(P<0.001)$ and the $400 \mu \mathrm{mol} / \mathrm{L}$ arginine group reduced the cytotoxicity more than the $50 \mu \mathrm{mol} / \mathrm{L}$ arginine group $(P<0.001)$. As revealed in Fig. 7 , the mRNA abundances of $I L-1 \beta, I L-8$, and $I L-10$ in $C$. perfringens-challenged group (group 2) were 717.20-fold $(P<0.001)$, 400.59-fold $(P<0.001)$ and 8.29-fold $(P<0.001)$ higher than that in the unchallenged group, respectively. The $50 \mu \mathrm{mol} / \mathrm{L}$ arginine group could not affect $I L-1 \beta$ and $I L-8$ mRNA expression but significantly decreased the $I L-10$ mRNA expression $(P<0.001)$ when compared with $C$.

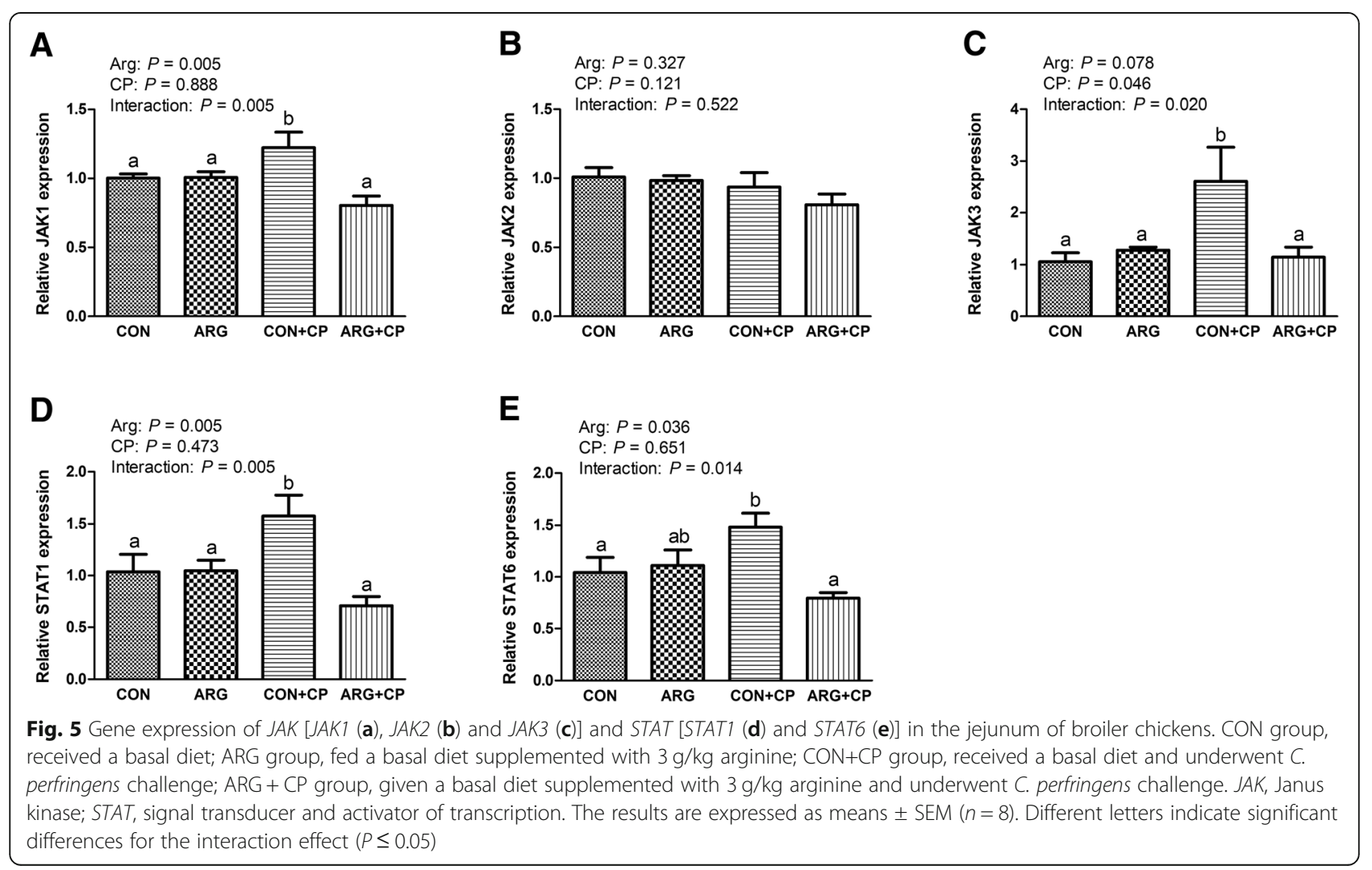




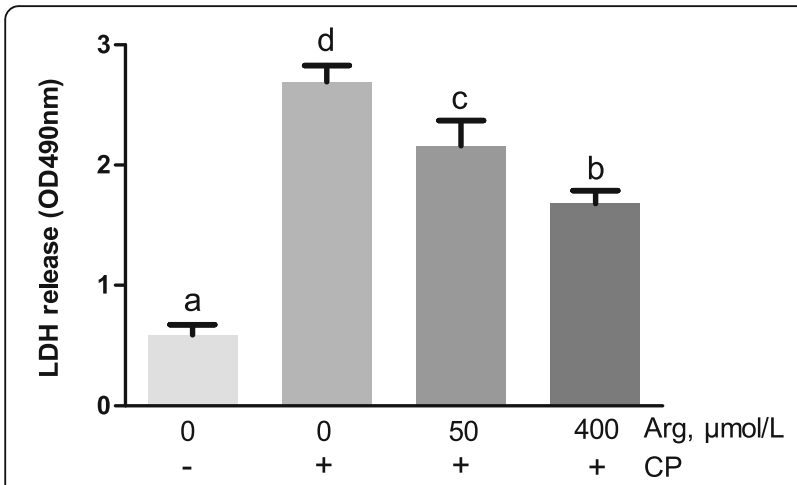

Fig. $6 \mathrm{LDH}$ release in supernatant of chicken intestinal epithelial cells stimulated with C. perfringens. Cells were cultured for $6 \mathrm{~h}$ in arginine-free DMEM/F12 containing 0, 50, $400 \mu \mathrm{mol} / \mathrm{L}$ arginine followed by incubating with or without $C$. perfringens for $4 \mathrm{~h}$; LDH, Lactic dehydrogenase. The results are expressed as means $\pm \operatorname{SEM}(n=6)$. Bars sharing different lowercase letters differ markedly $(P<0.05)$

perfringens-challenged group. The $400 \mu \mathrm{mol} / \mathrm{L}$ arginine group significantly reduced the increased mRNA abundances of $I L-1 \beta, I L-8$, and $I L-10$ caused by $C$. perfringens challenge $(P<0.001)$. Figure 8 exhibits that the mRNA expression of CAT-1 $(P<0.001)$ and CAT-3 $(P<0.05)$ was significantly stimulated in response to $C$. perfringens challenge. The increased mRNA expression of $C A T-1$ was markedly decreased by $50 \mu \mathrm{mol} / \mathrm{L}$ and $400 \mu \mathrm{mol} / \mathrm{L}$ arginine pre-treatment $(P<0.001)$. Furthermore, $50 \mu \mathrm{mol} / \mathrm{L}$ arginine group significantly decreased the increased $C A T-3$ mRNA expression induced by $C$. perfringens challenge $(P<0.05)$ while $400 \mu \mathrm{mol} / \mathrm{L}$ arginine group did not affect CAT-3 mRNA expression compared with $C$. perfringenschallenged group $(P>0.05)$.

\section{Discussion}

Gross lesion score and histopathological examination are commonly used for evaluating the severity of necrotic enteritis. In this study, increased intestinal lesion and histopathological injury scores were observed in C. perfringens challenged chickens relative to the control group, suggesting that $C$. perfringens infections led to inflammatory responses in the intestine. As each group of birds was kept in a rearing isolator and there was no replicate, so it is a pity that we did not determine the growth performance. For the $C$. perfringens-infected birds, arginine addition markedly decreased the intestinal gross pathological and histopathological lesion scores compared with the control diet group, indicating that arginine benefited the intestinal health. In addition, $C$. perfringens challenged birds exhibited higher levels of $C$. perfringens in the liver compared with the unchallenged birds, reflecting that $C$. perfringens challenge damaged gut barrier integrity. However, dietary arginine supplementation prevented the invasion of $C$. perfringens into the liver, suggesting that arginine addition played a positive role in controlling $C$. perfringens challenge. The in vitro results demonstrated that arginine pre-treatment attenuated the $C$. perfringens-induced amounts of $\mathrm{LDH}$, an indicator of cytotoxicity. In line with these results, our previous studies have reported that arginine supplementation could promote intestinal health, as indicated by improving intestinal absorption function, decreasing intestinal permeability and inhibiting intestinal $C$. perfringens population in the broilers under the conditions of subclinical necrotic enteritis [19].

Procalcitonin serves as a biomarker of severe bacterial infections [28]. In bacterial infections, bacterial endotoxins and inflammatory cytokines stimulate procalcitonin production in many tissues, such as liver, lung and kidney, and then, procalcitonin goes in circulation, leading to a marked increase in the serum procalcitonin concentration [29]. In our study, increased serum procalcitonin levels after $C$. perfringens challenge indicated a systemic inflammatory response, which also evidenced that the infectious model was successfully established.

Arginine availability in the digestive tract plays a key role in maintaining intestinal immune homeostasis under conditions of inflammation and infection [6]. Total body arginine

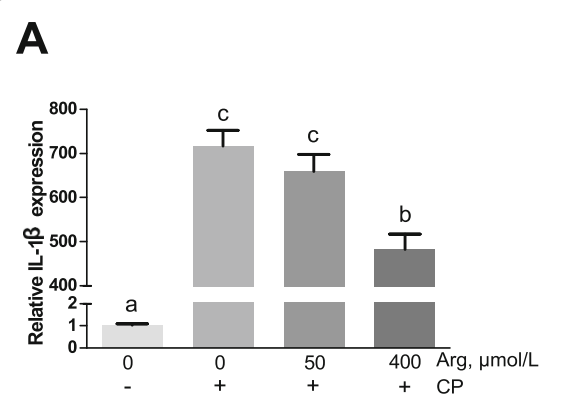

B

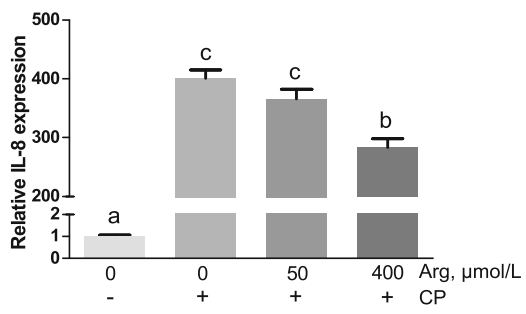

C

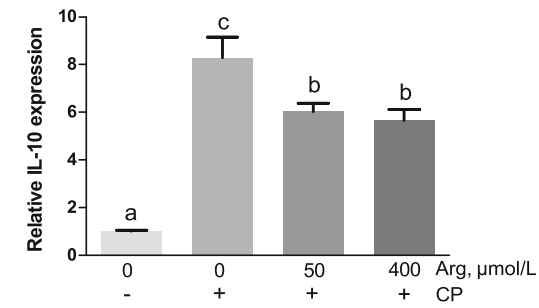

Fig. 7 Gene expression of cytokines $[I L-1 \beta(\mathbf{a}), I L-8(\mathbf{b})$ and $I L-10(\mathbf{c})]$ in chicken intestinal epithelial cells stimulated with C. perfringens. Cells were cultured for $6 \mathrm{~h}$ in arginine-free DMEM/F12 containing 0,50,400 $\mathrm{mmol} / \mathrm{L}$ arginine followed by incubating with or without $C$. perfringens for $4 \mathrm{~h}$. The results are expressed as means $\pm \operatorname{SEM}(n=6)$. Bars sharing different lowercase letters differ markedly $(P<0.05)$ 

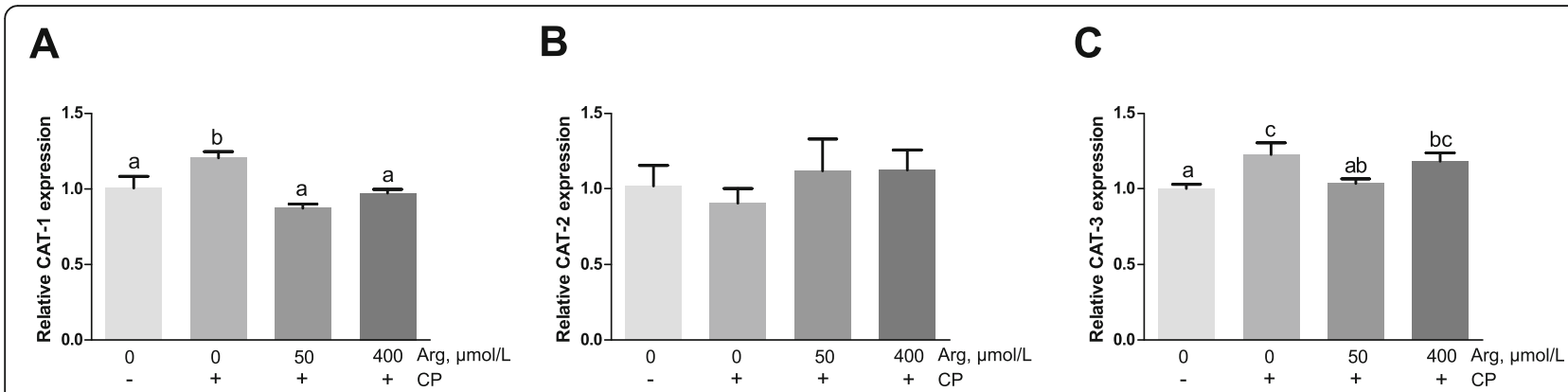

Fig. 8 Gene expression of CATs [CAT-1 (a), CAT-2 (b) and CAT-3 (c)] in chicken intestinal epithelial cells stimulated with C. perfringens. Cells were

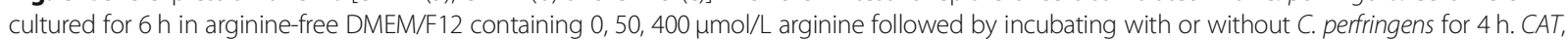
cationic amino acid transporter. The results are expressed as means $\pm \operatorname{SEM}(n=6)$. Bars sharing different lowercase letters differ markedly $(P<0.05)$

content has been found to be depleted in response to trauma or surgery [30]. However, whether C. perfringens infection induces a systemic arginine deficiency in broiler chickens remains unclear. In this study, C. perfringens-infected birds fed basal diets significantly reduced serum arginine levels compared to the uninfected birds fed basal diets, which indicated that an arginine deficiency developed in response to C. perfringens infection. Arginine administration has been shown to partially or completely reverse arginine deficiency-associated immunopathologies, ameliorating conditions such as intestinal ischemia, malabsorption, inflammation and infectious complications $[6,11,13]$, which supports our results.

In addition to nutrient digestion and absorption, the intestine also plays a key role in the immune response. Lysozyme, an important bacteriolytic component of the innate immune system, can hydrolyze glycosidic bonds in the peptidoglycan layer of Gram-positive bacterial cell walls [31]. Moreover, lysozyme inhibited the growth of C. perfringens and alpha toxin production [32]. Anaerobic cow mastitis induced by $C$. perfringens increased lysozyme activity in milk samples, which was positively correlated with disease severity [33]. Our results revealed that the elevated lysozyme activity in the jejunal mucosa caused by $C$. perfringens was reduced by arginine supplementation, likely because arginine alleviated the intestinal damage caused by the infection.

Cytokines are usually considered as markers of injury or infection [34]. Excessive production of pro-inflammatory cytokines may damage intestinal integrity and barrier function [35]. In the present study, C. perfringens challenge significantly increased the mRNA expression of proinflammatory cytokines in the jejunum of birds, which were decreased by arginine addition, indicating that arginine alleviated the excessive activation of inflammatory response. Similar results were also reported in many other stress models, such as burn [36], sepsis [37] and gut ischemia-reperfusion [38]. Besides, the in vivo study illustrated that arginine administration down-regulated the increased transcription of anti-inflammatory cytokines induced by
C. perfringens challenge. Tan et al. [39] reported that arginine addition could attenuate the increased transcription of both pro- and anti-inflammatory cytokines induced by lipopolysaccharide challenge in broiler chickens. In this in vitro study, the elevation of pro-inflammatory cytokines (IL-1 $\beta, 717.20$ fold; $I L-8,400.59$ fold) was much higher than that of anti-inflammatory cytokine (IL-10, 8.29 fold) when compared the only challenged cells with the unchallenged cells, indicating that pro-inflammatory response was dominant. However, arginine addition sharply decreased the elevation of $I L-1 \beta$ and $I L-8$ mRNA expression induced by $C$. perfringens challenge. These results suggested that the gut injury was reversed by arginine addition through suppression of pro-inflammatory cytokines overproduction.

The intestine is an essential site for maintaining body arginine homeostasis [7]. Arginine is actively metabolized in enterocytes, and arginine transmembrane transport is mainly performed by the CAT family of proteins, which act through a Na-independent transport system [8]. The CAT family contains four members, CAT-1, CAT-2, CAT-3 and CAT-4, in which CAT-1, CAT-2, and CAT-3 transport cationic amino acids such as arginine, ornithine, and lysine [40], while CAT-4 is reportedly unable to transport basic, neutral or acidic amino acids, and its physiological function remains unknown [41]. The present study showed that $C$. perfringens challenge increased CAT-1 and CAT-3 mRNA expression in chickens and IEC, and arginine treatment reduced $C A T-2$ and $C A T-3$ mRNA expression in the jejunum of chickens, and $C A T-1$ and $C A T-3$ mRNA expression in IEC. Similarly, Zheng et al. [42] showed that dietary arginine supplementation reversed the increased mRNA expression of CAT-1 induced by oxidative stress in the jejunum of weaned piglets. There are at least two factors in modulating arginine absorption. First, CAT mRNA content is regulated by substrate availability. Bogle et al. [43] found that arginine deprivation increased cationic amino acid transport in porcine aortic endothelial cells. This elevation may reflect adaptive responses in the CAT system. When arginine is sufficient, 
the expression of CATs is less [42]. Second, CATs expression was modulated by IL- $1 \beta$ and IFN- $\gamma$. Previous studies have shown that IL-1 $\beta$ and IFN- $\gamma$ stimulate arginine uptake, along with the Mrna expression of CAT-1 and CAT2 in rat cardiac microvascular endothelial cells [44]. In this study, arginine supplementation downregulated the transcription of $I L-1 \beta$ and IFN- $\gamma$, as well as that of CAT-2 in vivo, and suppressed the increased transcription of $I L-1 \beta$ and $C A T-1$ induced by $C$. perfringens challenge in vitro, which evidenced that $I L-1 \beta$ and $I F N-\gamma$ were involved in the regulation of CATs expression in chickens under $C$. perfringens challenge.

$L$-arginine is catabolized via multiple pathways mediated by iNOS, arginase, AGAT, and ADC, giving rise to nitric oxide, polyamines, proline, glutamate, creatine, and agmatine, as well as other products [9]. In our study, C. perfringens infection increased jejunal mRNA expression of $i N O S, A R G 2$ and $A D C$, as well as increasing iNOS activity in the jejunal mucosa, which stimulated arginine catabolism, leading to serum arginine deficiency. Dietary arginine supplementation normalized the overexpression of arginine catabolic enzymes, contributing to the maintenance of arginine homeostasis. But out of our expectation, the addition of arginine, the sole substrate of NO in body, did not increase the mRNA and protein level of iNOS but conversely decreased them in the C. perfringens-challenged birds. Similar findings were also reported by Zhao et al. [45] and Wu et al. [46]. The reasons why arginine decreased the $C$. perfringens-induced $i N O S$ mRNA expression and activities may be as follows. First, iNOS level and NO synthesis vary over time. Kosaka et al. [47] discovered that arginine supplementation counteracted the decrease in arginine levels and increased $\mathrm{NO}$ in the kidney in the earliest phase (45 min) of ischemia-reperfusion in rats, however, it downregulated the increased plasma NO as well as renal iNOS mRNA and protein expression at $7 \mathrm{~h}$ of ischemia-reperfusion. In our study, arginine administration may promote NO synthesis in the earliest phase of C. perfringens challenge, which then in turn inhibited excessive expression of $i N O S$ gene [48] in order to avoid damages caused by excessive NO. Second, arginine may be preferentially catalyzed to ornithine by ARG 1 . There are two forms of arginase: the cytoplasmic type ARG1 and the mitochondrial type ARG2 [11]. Arginase competes with iNOS for the common substrate, $L$-arginine. However, we did not determine ARG1 mRNA expression in our study because the gene sequence of ARG1 in chickens is not uncovered. Agmatine produced by ADC has no deleterious effects on bacteria and can be effectively used as an energy source by the pathogen [49]. Recently, an in vitro experiment showed that lipopolysaccharide (LPS) plus cytokines (IL- $1 \beta$, IFN- $\gamma$ and TNF- $\alpha$ ) could upregulate the arginine decarboxylase pathway in astrocytes and the macrophage-like cell line RAW 264.7, resulting in increased agmatine production [50]. AGAT catalyzes the rate-limiting step of creatine production, and there are few studies on the role of AGAT in intestinal inflammation. Recently, creatine was found to protect against colitis in homozygous AGAT mutant mice [51]. In our study, the result that arginine administration decreased the mRNA expression of $i N O S, A R G 2, A D C$ and $A G A T$ in the jejunum of chickens suggested that arginine alleviated the inflammatory injury after $C$. perfringens challenge-induced acute inflammation.

The JAK-STAT cascade is a critical signaling pathway in the inflammatory responses [15]. In the canonical JAK-STAT pathway, LPS or cytokine binding to its receptors induces JAK phosphorylation, which in turn phosphorylates STATs. Then, phosphorylated STATs form homodimers or heterodimers and translocate to the nucleus to regulate target gene transcription, including genes of other pro-inflammatory cytokines, chemokines, and inducible enzymes such as iNOS [16, 17]. Due to the deficiency of appropriate antibodies available for use in studies of chickens, we did not determine the protein levels and phosphorylation status of components in this signaling pathway. In the present study, the infected chickens increased jejunal JAK1, JAK3, STAT1 and STAT6 mRNA expression compared to uninfected birds. Consistently, some studies have reported that the mRNA levels of JAK-STAT pathway were changed after pathogen challenge. Truong et al. [18] demonstrated that mRNA expression of JAK1, JAK3, and STAT1 was significantly increased in the spleen of broilers suffering from necrotic enteritis as compared with that of healthy birds. Besides, according to the RNA-Seq data, 29 and 19 differentially expressed genes were mapped to JAKSTAT signaling pathways in the spleens of Marek's disease resistant chicken line and susceptible line co-infected with Eimeria maxima/C. perfringens compared to control, respectively [52]. In this study, arginine administration inhibited the $C$. perfringens challenge-induced gene expressions involved in the JAK-STAT pathway. Dörpinghaus et al. [53] reported that the inhibition of STAT1 expression downregulated iNOS transcription, which can alleviate LPS-induced cytotoxicity in macrophages and microglial cells. Ashino et al. [54] have proven that the selective inhibition of JAK $1 / 3$ reduced STAT6 and STAT5 phosphorylation and Th2 cytokine production, which suppressed the development of airway hyperresponsiveness. The results of our study revealed that the downregulation of activated JAK-STAT pathways was a possible mechanism by which arginine attenuated $C$. perfringens-induced gene expression of iNOS and some pro-inflammatory cytokines. In the present study, the changes of STATs at mRNA level may be related with the non-canonical pathway involving 
unphosphorylated STATs. Recently, some researchers uncovered that the unphosphorylated STAT3 could compete with I $\mathrm{kB}$ for binding to unphosphorylated $\mathrm{NF}-\mathrm{kB}$, translocating to the nucleus and participating in the activation of a subset of NF- $\mathrm{kB}$-dependent genes [55]. Unphosphorylated STAT6 was suggested to bind to a consensus STAT6 binding site in the promoter of the $\mathrm{COX}-2$ gene, regulating its constitutive expression [55].

\section{Conclusions}

Dietary $L$-arginine supplementation prevented the circulating arginine deficiency induced by $C$. perfringens challenge and reversed $C$. perfringens challenge-upregulated gene expression of inflammatory cytokines, arginine transporters and arginine catabolic enzymes in the intestine of broiler chickens. The attenuation of the inflammatory response by arginine was at least partly via inhibition of JAK-STAT signalling pathways. These results indicate that arginine supplementation can be used as a potential preventive approach against avian necrotic enteritis.

\section{Abbreviations}

ADC: Arginine decarboxylase; AGAT: Arginine:glycine amidinotransferase; ARG + CP: Birds received a basal diet supplemented with $3 \mathrm{~g} / \mathrm{kg}$ arginine and C. perfringens challenge; ARG: Birds received a basal diet supplemented with $3 \mathrm{~g} / \mathrm{kg}$ arginine; ARG2: Arginase 2; CAT: Cationic amino acid transporter; CON: Birds received a basal diet; $\mathrm{CON}+\mathrm{CP}$ : birds received a basal diet and $\mathrm{C}$. perfringens challenge; DMEM/F12: Dulbecco's Modified Eagles Medium/ Nutrient Mixture F-12; HPLC: High-performance liquid chromatography; IEC: Intestinal epithelial cells; iNOS: Inducible nitric oxide synthase; JAK: Janus kinase; LDH: Lactic dehydrogenase; MOI: Multiplicity of infection; PBS: Phosphate-buffered saline; STAT: Signal transducer and activator of transcription

\section{Acknowledgements}

The authors acknowledge American Journal Experts (http://www.aje.com) for its linguistic assistance.

\section{Authors' contributions}

BZ conducted the animal trial, analysed the samples and wrote the manuscript. LG contributed to the animal feeding and sample analyses. DL and MS assisted with the manuscript preparation. ZL and HF helped with sample collection and data analyses. YG contributed to the experimental design and manuscript amendment. All authors read and approved the final manuscript.

\section{Funding}

This project was funded by the Modern China Agricultural Research System Program (CARS-41-G11).

\section{Availability of data and materials}

All data generated or analysed during this study are available from the corresponding author by request. The datasets supporting the conclusions of this article are included in the article.

\section{Ethics approval and consent to participate}

The experiments were approved by the Animal Care and Use Committee of China Agricultural University.

\section{Consent for publication}

Not applicable.

\section{Competing interests}

The authors declare that they have no competing interests.
Received: 12 January 2019 Accepted: 7 June 2019

Published online: 12 August 2019

\section{References}

1. Wade B, Keyburn A. The true cost of necrotic enteritis. World Poult. 2015:31:16-7.

2. Van Immerseel F, De Buck J, Pasmans F, Huyghebaert G, Haesebrouck F, Ducatelle R. Clostridium perfringens in poultry: an emerging threat for animal and public health. Avian Pathol. 2004;33:537-49.

3. Shojadoost B, Vince AR, Prescott JF. The successful experimental induction of necrotic enteritis in chickens by Clostridium perfringens: a critical review. Vet Res. 2012;43:74.

4. Tamir $\mathrm{H}$, Ratner $\mathrm{S}$. Enzymes of arginine metabolism in chicks. Arch Biochem Biophys. 1963;102:249-58.

5. Popovic PJ, Zeh HJ, Ochoa JB. Arginine and immunity. J Nutr. 2007;137: 1681S-6S.

6. Fritz JH. Arginine cools the inflamed gut. Infect Immun. 2013;81:3500.

7. Wu G, Bazer FW, Davis TA, Jaeger LA, Johnson GA, Kim SW, et al. Important roles for the arginine family of amino acids in swine nutrition and production. Livest Sci. 2007;112:8-22.

8. Stevens BR. Amino acid transport in intestine. In: Kilberg MS, Häussinger D, editors. Mammalian Amino Acid Transport. New York: Plenum; 1992. p. 149-163.

9. Morris SM. Arginine metabolism revisited. J Nutr. 2016;146:2579S-86S.

10. Coburn LA, Horst SN, Allaman MM, Brown CT, Williams CS, Hodges ME, et al. L-arginine availability and metabolism is altered in ulcerative colitis. Inflamm Bowel Dis. 2016;22:1847-58.

11. Gobert AP, Cheng Y, Akhtar M, Mersey BD, Blumberg DR, Cross RK, et al. Protective role of arginase in a mouse model of colitis. J Immunol. 2004;173:2109-17.

12. Drover JW, Dhaliwal R, Weitzel L, Wischmeyer PE, Ochoa JB, Heyland DK. Perioperative use of arginine-supplemented diets: a systematic review of the evidence. J Am Coll Surg. 2011;212:385-99 e381.

13. Chau JY, Tiffany CM, Nimishakavi S, Lawrence JA, Pakpour N, Mooney JP, et al. Malaria-associated L-arginine deficiency induces mast cell-associated disruption to intestinal barrier defenses against nontyphoidal Salmonella bacteremia. Infect Immun. 2013:81:3515-26.

14. Wu G, Bazer FW, Davis TA, Kim SW, Li P, Marc Rhoads J, et al. Arginine metabolism and nutrition in growth, health and disease. Amino Acids. 2009; 37:153-68.

15. Okugawa S, Ota Y, Kitazawa T, Nakayama K, Yanagimoto S, Tsukada K, et al. Janus kinase 2 is involved in lipopolysaccharide-induced activation of macrophages. Am J Phys Cell Phys. 2003;285:C399-408.

16. Kisseleva T, Bhattacharya S, Braunstein J, Schindler C. Signaling through the JAK/STAT pathway, recent advances and future challenges. Gene. 2002:285:1-24.

17. Kovarik P, Mangold M, Ramsauer K, Heidari H, Steinborn R, Zotter A, et al. Specificity of signaling by STAT1 depends on $\mathrm{SH} 2$ and C-terminal domains that regulate Ser727 phosphorylation, differentially affecting specific target gene expression. EMBO J. 2001;20:91-100.

18. Truong $A D$, Rengaraj $D$, Hong $Y$, Hoang $C T$, Hong $Y H$, Lillehoj $H S$. Differentially expressed JAK-STAT signaling pathway genes and target microRNAs in the spleen of necrotic enteritis-afflicted chicken lines. Res Vet Sci. 2017;115:235-43.

19. Zhang B, Lv Z, Li H, Guo S, Liu D, Guo Y. Dietary L-arginine inhibits intestinal Clostridium perfringens colonisation and attenuates intestinal mucosal injury in broiler chickens. Br J Nutr. 2017;118:321-32.

20. Liu D, Guo SS, Guo YM. Xylanase supplementation to a wheat-based diet alleviated the intestinal mucosal barrier impairment of broiler chickens challenged by Clostridium perfringens. Avian Pathol. 2012;41:291-8.

21. Dahiya JP, Hoehler D, Wilkie DC, Van Kessel AG, Drew MD. Dietary glycine concentration affects intestinal Clostridium perfringens and lactobacill populations in broiler chickens. Poult Sci. 2005;84:1875-85.

22. Jerzsele A, Szeker K, Csizinszky R, Gere E, Jakab C, Mallo JJ, et al. Efficacy of protected sodium butyrate, a protected blend of essential oils, their combination, and bacillus amyloliquefaciens spore suspension against artificially induced necrotic enteritis in broilers. Poult Sci. 2012; 91:837-43.

23. Wu G, Meininger CJ. Analysis of citrulline, arginine, and methylarginines using high-performance liquid chromatography. Methods Enzymol. 2008; 440:177-89. 
24. Wang W, Li Z, Lv Z, Zhang B, Lv H, Guo Y. Effects of Kluyveromyces marxianus supplementation on immune responses, intestinal structure and microbiota in broiler chickens. PLoS One. 2017;12:e0180884.

25. Livak KJ, Schmittgen TD. Analysis of relative gene expression data using real-time quantitative $P C R$ and the $2(T)(-$ Delta Delta C) method. Methods. 2001;25:402-8

26. Guo S, Li C, Liu D, Guo Y. Inflammatory responses to a Clostridium perfringens type a strain and a-toxin in primary intestinal epithelial cells of chicken embryos. Avian Pathol. 2015;44:81-91.

27. Guo S, Liu D, Zhang B, Li Z, Li Y, Ding B, et al. Two Lactobacillus species inhibit the growth and alpha-toxin production of Clostridium perfringens and induced Proinflammatory factors in chicken intestinal epithelial cells in vitro. Front Microbiol. 2017:8:2081

28. Lippi G, Sanchis-Gomar F. Procalcitonin in inflammatory bowel disease: drawbacks and opportunities. World J Gastroenterol. 2017;23:8283.

29. Mehanic S, Baljic R. The importance of serum procalcitonin in diagnosis and treatment of serious bacterial infections and sepsis. Mater Sociomed. 2013;25:277.

30. Davis JS, Anstey NM. Is plasma arginine concentration decreased in patients with sepsis? A systematic review and meta-analysis. Crit Care Med. 2011;39:380-5.

31. Phillips DC. The three-dimensional structure of an enzyme molecule. Sci Am. 1966;215:78-93.

32. Zhang G, Darius S, Smith S, Ritchie S. In vitro inhibitory effect of hen egg white lysozyme on Clostridium perfringens type a associated with broiler necrotic enteritis and its a-toxin production. Lett Appl Microbiol. 2006;42:138-43.

33. Osman KM, El-Enbaawy MI, Ezzeldin NA, Hussein HM. Nitric oxide and lysozyme production as an impact to Clostridium perfringens mastitis. Comp Immunol Microbiol Infect Dis. 2010;33:505-11.

34. Ertel W, Morrison MH, Wang P, Ba ZF, Ayala A, Chaudry IH. The complex pattern of cytokines in sepsis. Association between prostaglandins, cachectin, and interleukins. Ann Surg. 1991;214:141.

35. McKay DM, Baird AW. Cytokine regulation of epithelial permeability and ion transport. Gut. 1999:44:283-9.

36. Cui XL, Iwasa M, Iwasa Y, Ogoshi S. Arginine-supplemented diet decreases expression of inflammatory cytokines and improves survival in burned rats. JPEN J Parenter Enteral Nutr. 2000;24:89-96.

37. Yeh $\mathrm{CL}$, Yeh SL, Lin MT, Chen WJ. Effects of arginine-enriched total parenteral nutrition on inflammatory-related mediator and T-cell population in septic rats. Nutrition. 2002:18:631-5.

38. Fu TL, Zhang WT, Zhang L, Wang F, Gao Y, Xu M. L-arginine administration ameliorates serum and pulmonary cytokine response after gut ischemiareperfusion in immature rats. World J Gastroenterol. 2005;11:1070-2.

39. Tan JZ, Liu SS, Guo YM, Applegate TJ, Eicher SD. Dietary l-arginine supplementation attenuates lipopolysaccharide-induced inflammatory response in broiler chickens. Br J Nutr. 2014;111:1394-404.

40. Verrey F, Closs El, Wagner CA, Palacin M, Endou H, Kanai Y. CATs and HATs: the SLC7 family of amino acid transporters. Pflugers Arch. 2004;447:532-42.

41. Closs El, Boissel JP, Habermeier A, Rotmann A. Structure and function of cationic amino acid transporters (CATs). J Membr Biol. 2006;213:67-77.

42. Zheng P, Yu B, He J, Yu J, Mao X, Luo Y, et al. Arginine metabolism and its protective effects on intestinal health and functions in weaned piglets under oxidative stress induced by diquat. Br J Nutr. 2017;117:1495-502.

43. Bogle RG, Baydoun AR, Pearson JD, Mann GE. Regulation of L-arginine transport and nitric oxide release in superfused porcine aortic endothelial cells. J Physiol. 1996;490:229-41.

44. Simmons WW, Closs El, Cunningham JM, Smith TW, Kelly RA. Cytokines and insulin induce cationic amino acid transporter (CAT) expression in cardiac myocytes. Regulation of $\mathrm{L}$-arginine transport and no production by CAT-1, CAT-2A, and CAT-2B. J Biol Chem. 1996;271:11694-702.

45. Zhao FF, Wu TY, Wang HR, Ding LY, Ahmed G, Li HW, et al. Jugular arginine infusion relieves lipopolysaccharide-triggered inflammatory stress and improves immunity status of lactating dairy cows. J Dairy Sci. 2018;101:5961-70

46. Wu T, Wang C, Ding L, Shen Y, Cui $H$, Wang M, et al. Arginine relieves the inflammatory response and enhances the casein expression in bovine mammary epithelial cells induced by lipopolysaccharide. Mediat Inflamm. 2016;2016:9618795.

47. Kosaka H, Yoneyama H, Zhang L, Fujii S, Yamamoto A, Igarashi J. Induction of LOX-1 and iNOS expressions by ischemia-reperfusion of rat kidney and the opposing effect of L-arginine. FASEB J. 2003;17:636-43.
48. Colasanti M, Persichini T, Menegazzi M, Mariotto S, Giordano E, Caldarera $\mathrm{CM}$, et al. Induction of nitric oxide synthase mRNA expression. Suppression by exogenous nitric oxide. J Biol Chem. 1995;270:26731-3.

49. Paulson NB, Gilbertsen AJ, Dalluge JJ, Welchlin CW, Hughes J, Han W, et al. The arginine decarboxylase pathways of host and pathogen interact to impact inflammatory pathways in the lung. PLoS One. 2014;9:e111441.

50. Regunathan S, Piletz JE. Regulation of inducible nitric oxide synthase and agmatine synthesis in macrophages and astrocytes. Ann N Y Acad Sci. 2003; 1009:20-9.

51. Turer E, MCAlpine W, Wang KW, Lu T, Li X, Tang M, et al. Creatine maintains intestinal homeostasis and protects against colitis. Proc Natl Acad Sci U S A. 2017;114:E1273-e1281.

52. Truong AD, Hong YH, Lillehoj HS. RNA-seq profiles of immune related genes in the spleen of necrotic enteritis-afflicted chicken lines. AsianAustralas J Anim Sci. 2015:28:1496-511.

53. Dörpinghaus M, Brieger A, Panichkina O, Rink L, Haase H. Lead ions abrogate lipopolysaccharide-induced nitric monoxide toxicity by reducing the expression of STAT1 and iNOS. J Trace Elem Med Biol. 2016;37:117-24.

54. Ashino S, Takeda K, Li H, Taylor V, Joetham A, Pine PR, et al. Janus kinase 1/ 3 signaling pathways are key initiators of $\mathrm{TH} 2$ differentiation and lung allergic responses. J Allergy Clin Immunol. 2014;133:1162-74.

55. Majoros A, Platanitis E, Kernbauer-Holzl E, Rosebrock F, Muller M, Decker T. Canonical and non-canonical aspects of JAK-STAT signaling: lessons from interferons for cytokine responses. Front Immunol. 2017:8:29.
Ready to submit your research? Choose BMC and benefit from:

- fast, convenient online submission

- thorough peer review by experienced researchers in your field

- rapid publication on acceptance

- support for research data, including large and complex data types

- gold Open Access which fosters wider collaboration and increased citations

- maximum visibility for your research: over $100 \mathrm{M}$ website views per year

At BMC, research is always in progress.

Learn more biomedcentral.com/submissions 